\title{
NGOs in Post Disaster Reconstruction in Aceh
}

\section{Norhazlina Fairuz Musa Kutty}

Department of Strategic Studies, Faculty of Defence Studies \& Management, National Defence University of Malaysia, Sungai Besi Camp, 57000 Kuala Lumpur.

Correspondence Author: Norhazlina Fairuz Musa Kutty, Department of Strategic Studies, Faculty of Defence Studies \& Management, National Defence University of Malaysia, Sungai Besi Camp, 57000 Kuala Lumpur.

Tel: +601390513400 ext. 2216; E-mail: nfairuz@upnm.edu.my

Received date: 12 January 2018, Accepted date: 20 June 2018, Online date: 2 July2018

Copyright: (C) 2018 Norhazlina Fairuz Musa Kutty. This is an open-access article distributed under the terms of the Creative Commons Attribution License, which permits unrestricted use, distribution, and reproduction in any medium, provided the original author and source are credited.

\begin{abstract}
This paper intends to analyse the relations and challenges facing non-state actor in developing and rebuilding post-tsunami Aceh, Indonesia. The main objective of this paper was to look at the different challenges facing various government and nongovernment stakeholders during the reconstruction and rehabilitation (RR) process in redeveloping and rebuilding post disaster areas. The second objective of the paper was to examine the effects on capacity building via participatory development. The roles of civil society organisations like INGOs and NGOs as programmes implemented in post disaster development promise rapid and better solution depending on cooperation and coordination between state and non-state actors. However, the level of participation from the affected communities as beneficiaries of the programmes and projects has strong effect on their capacity building in development phase. In regard to this, the focus of the paper is to examine the effect of participation of beneficiaries in the programmes as means of empowerment toward to capacity building. The outcome of RR programmes relates closely on level of beneficiaries participation. The levels of participation also determine whether the programmes had been successfully carried out to ensure smooth transition into developmental phase. Beside participation effort from the beneficiaries collaboration and coordination between NGOs and government agencies is crucially important factor in determining effective programmes outcomes. The combination of aid and support from international agencies such as donors and NGOs and good coordination from government agencies (Agencies for Rehabilitation and Reconstruction) are needed to encourage higher participation level, which will empower the beneficiaries' capacity building toward community capability in the developmental phase. The paper will focus on the theoretical and conceptual explanation linking the relationship between participatory approach in development and the outcomes of programmes and projects in developmental phase and its effects of capacity building. The second part of this paper will focus on the outcome from programs and projects in Emergency relief and recovery phase (ERR) and reconstruction and rehabilitation (RR) phase in Aceh Indonesia after the December 2004 Tsunami. The discussions of this paper were heavily based on empirical finding of actual outcomes of these two phase of Post Tsunami Reconstruction (PTR) in Aceh extracted from data collections in the developmental phase (2009-2013).
\end{abstract}

Key words: Post tsunami reconstruction; participation; Rehabilitation and Reconstruction (RR); NGOs; Emergency relief and recovery (ERR); LRRD and capacity building

\section{INTRODUCTION}

This paper examines the involvement of non-governmental organisations in post tsunami reconstruction in Aceh. In particular, it considers their contribution toward the attainment of capacity building during the developmental phase (2009-2014). Previous studies have viewed this role from the perspective of the NGOs whereas this paper seeks to by TEC and non governmental agencies only self examine the role played by the NGOs from their own perspective, excluding the beneficiaries. Based on initial analysis of the empirical data collected during interviews with main tsunami aid stakeholders, the beneficiaries and the NGOs indicates the importance of the NGOs' role in encouraging local participation in the Rehabilitation and Reconstruction (RR) programmes to help build their local beneficiaries capacity. The paper builds an analytical/constructive framework based on participatory development, NGOs and Link between Rehabilitation, Reconstruction and Development (LRRD) within which to situate the study.[9] The later part of the paper discusses NGOs' role in Post-Tsunami Reconstruction in Aceh, Indonesia. Key terms include development, participation, LRRD and capacity building.

\section{Post Tsunami Aceh after 10 years:}

The month of December 2014 marked the $10^{\text {th }}$ anniversary of the tsunami disaster in Aceh, Indonesia. The tsunami that hit Banda Aceh and its surrounding districts caused a massive number of casualties and loss of life. Out of 151,976 total casualties caused by the Indian Ocean Earthquake and Tsunami, more than 126,195 casualties were in Aceh, Indonesia. Apart from this more than 517,000 people lost their houses and many more were lost or taken by the tsunami waves back to the sea [1]. More than 430,000 were displaced and most of them lost their families and possessions According to Tsunami Museum in Banda Aceh, the total population of Aceh before the tsunami was estimated about 4,271,000 and after the tsunami it had been reduced to 4,031,589. The tsunami also destroyed more than 300 kilometers of coastline [1]. The tsunami also affected other main cities Callang and Meulaboh in West Aceh. Besides the epicenter of the earthquake in Aceh are much closer to the city of Meulaboh compared to Banda Aceh. 
Another factor contributing to high casualties was the fact that $90 \%$ per cent of local communities in West Aceh depend on the fisheries and agriculture as their income and represent the largest socioeconomic activities. The coastal population in Banda Aceh and West Aceh chooses to live about five to ten kilometers from the sea to sustain their livelihood in Aceh.

\section{Methodology:}

The sampling for respondent adopted snowballing technic based on key informant in both major regency in Aceh, namely Banda Aceh and West Aceh regency that include Aceh Besar, Aceh Jaya, Pidie Jaya, Lumno, Callang and Meulaboh. The sixty participant of this sampling was cautiously selected with the assistance of key informants, which were also co-researchers in Tsunami and Disaster Mitigation Research Centre (TDMRC), Syiah Kuala University, Banda Aceh Indonesia to ensure smooth data sampling throughout the data collection process. The methods applied were both in depth interviews and focus group discussion (FGD) with affected communities and INGOs. The method of analysis of these empirical finding is qualitative based.

\section{RESULT AND DISCUSSION}

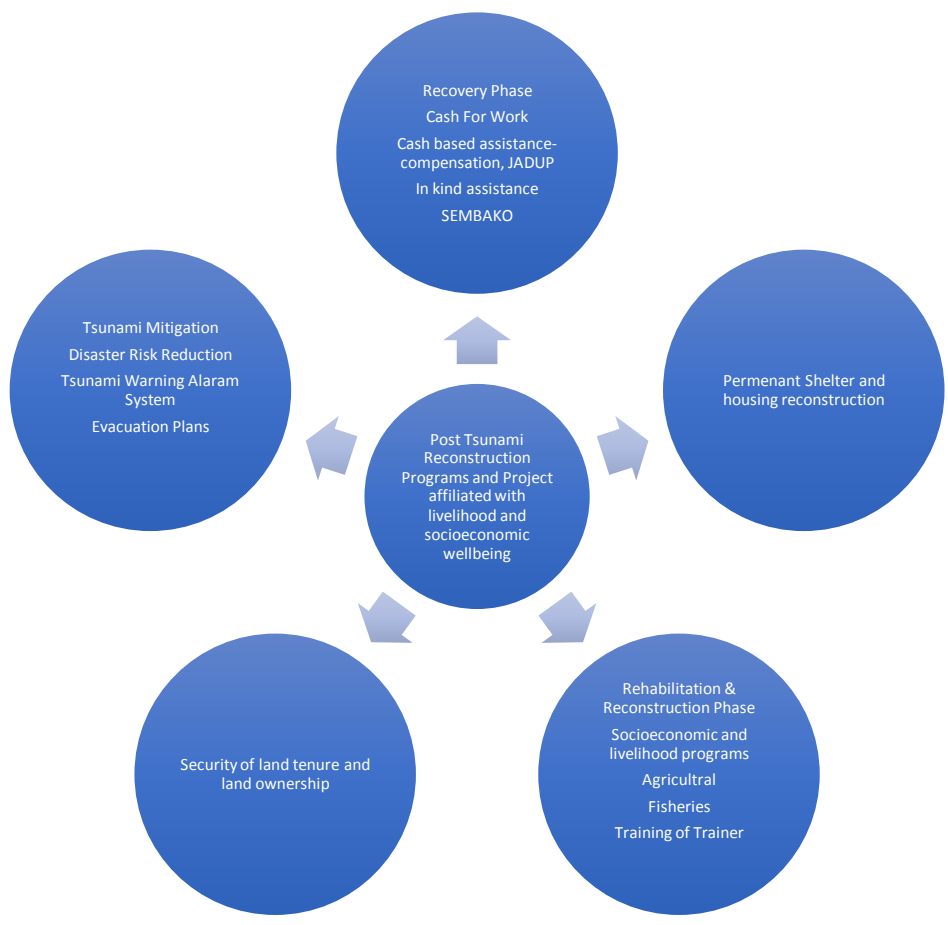

Fig. 1: Programmes and projects affecting livelihood and socioeconomic well being of Affected Communities in Aceh, Indonesia.

There are two sides of NGO that need consideration when analyzing their role as agent of development in Post-Tsunami-Reconstruction [2] Given the appropriate funding, timing and good state-NGO coordination and collaboration to some extent this increases their downward accountability [2] to the empowerment of the beneficiaries or their constituencies. On the other hand, the downward accountability also forces NGOs to restrain direct and indirect exclusion the local leaders at district and region level as a result fearing mismanagement of funding causing their beneficiaries not being able to enjoy the full benefits of the reconstruction. Factors such as corruptive local and central government, needed to be weighed in as an indirect result affecting NGO accountability in aid delivery. However, when the local leaders is taken out of the process of reconstruction, this weight higher responsibility for NGOs to develop and monitor a local committee that function to oversee the progress of the programmes and reconstruction programmes.

The informally selected of committee member by the villagers was one of the alternatives for the NGO to avoid the negligence of the local leaders and avoid the mismanagement of the whole reconstruction programmes. The local committee is rather crucially important to be included in the reconstruction planning and implementation to enhances outcome in human capacity aspects via beneficiaries' direct participation and NGOs effectiveness to empower the local communities and reach their targeted beneficiaries without the lengthy bureaucratic delays.

NGOs programmes especially those from the Western part of the world usually been planned and designed based on general post-disaster assessment. This is usually based on NGOs' other disaster operation experiences, which increases the tendency of generalisation of aid and assistance and high propensity of neglecting the actual need and assessment. Here the likelihood of local need, knowledge, expertise and values not accommodated into the programmes are rather high given the large scale and impact of disaster like tsunami 2004.

Primary finding from this research shows that most programmes only included unpretentious participation which fall into the categories of manipulative and consultative participation based programmes. Both categories indicate that the planning and implementation of the programmes only include informal local input and expertise. These two types of participatory approach in programmes somehow diminish the chance for building local ownership or partnership of the programmes. Partnership and ownership type of participatory would have more chances of local proprietorship and legitimacy being integrated in the programmes. Higher level of participation also promises more effectiveness and continuity and assimilation of outcomes of programmes in long-term development programmes.[8]

NGO in Development: Participation and capacity building in reconstruction:

Participation is generally defined as 'the action of taking part in something'[3]. As described earlier the participatory approach in the rehabilitation and reconstruction phase is a crucial factor for developmental projects and programmes to benefit the AC better. The inclusion of beneficiaries as part of planning and programming stage in post disaster are usually only by initial consultation with the surviving communities. It all depends on the scale of the disaster. The inclusion of the local communities as part of the programmes and project will however promise a better outcome of the whole reconstruction process.

An effective RR means programmes and projects have high level of local participation and ownership. Higher participation will result in the community owning the program and project and they would easily sustain it into another stage which developmental phase. The developmental stage of RR programmes and projects would reflect the success of the RR phase itself. Development is not only just externally driven and technical and economic intervention but involves respecting, listening to and working with local people. Under the developmental paradigm the promise of empowerment of local people starts with establishment of a method for participatory development. 
Reconstruction from below is an intervention by NGO from bottom-up fashion where it goes beyond state institution [4]. This kind of reconstruction is becoming a mainstream in NGOs intervention in post war and post disaster communities. The question of why beyond state explain a lots of challenges faces the NGO when the reconstruction done in top-bottom manners. The most prevailing issues is pertaining is the ongoing mistrust in local organization including the state and non-state institutions.

Reconstruction also means that rebuilding and rehabilitating post disaster or post conflict communities which also known as socioeconomic recovery in 'fragile' states. It is an integrated process designed to reactivate the development and at the same time create a peaceful state. Here development is seen as important part of peace under the notion 'No Peace Without development and No Development Without Peace'. The main purpose of reconstruction is to ensure that the programmes and projects can be sustained into a developmental phase. This also means that to ensure state, societies and economies do not relapse and need to be transformed for better human development.

In Reconstruction and Rehabilitation (RR) in Aceh in post tsunami, there were two major themes of reconstruction and transformation: 'building back better' and 'building back safer'. Obviously the top-bottom reconstruction lead by the BRR (Badan Rehabilitasi dan Rekonstruksi) only plans to build but not to transform the community. Their reconstruction stops at the physical reconstruction of the facilities without multi sectorial support for the local communities' sustainable livelihood. BRR took off with no intention of looking into developmental phase, which includes socioeconomic development such as the continuity of livelihood, institution buildings and basic service provision.[13]

On the other hand, the term development from below is more familiar with INGOs planning and programmes. However, further discussion is needed to look at how far does this new alternative for reconstruction being embraced by the INGOs into their programmes and planning in RR in Aceh, Indonesia. But first, some initial discussion on the link between development and the importance of participation and its relevancy on INGO being the main advocates [5] of the development from below in case of Aceh Indonesia.

The term reconstruction from below is an approach that has embraced the element of "humble consociationalism" such as cautious interventions, reluctance to impose modernization agendas, working with what already exist and collaborative governance with mainly local actors. This approach is seen as an alternative to reconstruction, which also carries the notion of development from below. The notion of reconstruction from below brought with it the idea of 'development from below'.

The development intervention is associated closely with the primacy of local needs over development models, endogenous processes and participative decision-making which means putting people first and mainly it is considered as learning process for both INGOs and their beneficiaries. The term below carries the idea of starting everything at local level rather than being planned and decided outside the focus area being the headquarters of INGO before assessment done at local level. The focus on local also means that the people are the foremost element of the development process. Metaphorically below can be defined as 'empirically grounded and context specific policies to endogenous development and the promotion of local ownership; building on spontaneous processes rather than engineered ones 'inclusive in respecting non state actors'. Mainly the intervention for development needs to have a local focus and avoid the idea of autonomous and spontaneous process of reconstruction.

The NGOs should encourage the inclusion of local direct participant is rather important in the planning stage. As in the case of direct participant, it will help the affected communities (AF) to plan and determine the program according to their need and suitability than inclusion of the beneficiaries only at in the implementation stage. It is the best that the beneficiaries have given some sense of ownership in undertaking the program, that will help them direct and decide to what will best suits in their communities. Program planning based on viable capacity building activities being included is crucial to encourage local participation. Here the local communities input on such as their existing expertise, knowledge and skill should be considered as preexisting asset that needed to be in cooperated with NGOs programmes planning.

From capacity building perspective, the programmes should be constructed as a means to ensure the community and individuals respond better to social change. Here capacity building is seen as means to specified end and as and end itself. Capacity building 'can refer to specific approaches, strategies and methodologist used for the purpose of improving the performance of individuals, groups and organizations to carry out particular functions' [6].

Capacity building is also important as a mean to an end where it generates an ongoing process that is important for all human endeavors. NGOs need to encourage sense of ownership and legitimacy of the programmes for the locals in post tsunami RR programmes in order to help build their capacity. The second dimension of capacity building concerns the object of the process. Here it could be anything from individual; groups such as villagers; organization such as NGOs; sectors such as business, government and civil society and nations [7].

There are four main concerns in capacity building, first as a means to specific ends, second the object of capacity building, third the different methodologies of capacity buildings, and finally the purpose of capacity building. Sue Kenny, (2010) [8] emphasized that:

"...Critical to understanding the many forms of capacity building is the way in which programmes are conceptualized, developed and implemented. Thus the fifth way of understanding capacity building concerns whether capacity that is top-down or bottom-up. The top down approach aims to improve people's capacity to carry out preordained functions and objectives more effectively and efficiently."[7]

She also suggested that on using capacity building as a means in external intervention such as NGOs programmes in post disaster, which is a form of external intervention. “...capacity building activities can be used both donors/sponsors and beneficiaries of programmes as a path to legitimacy" [1]. In relation to encourage local participation, NGOs should include capacity building activities in their programmes which will create sense of ownership and legitimacy from the beneficiaries perspective in post tsunami reconstruction in Aceh. [1]

Considering the relationship between NGOs, state and their beneficiaries, capacity building is achievable through higher participation and input from the local. This however seems very complicated but eventually will benefit the communities and the state later in development planning where one's own capacity is deemed crucial in promising good outcome in the developmental phase. So the coordination and collaborations between the NGOs with local state apparatus and local NGO will help enhance better outcome of the program which in right mind should benefit the beneficiaries and help them gain sustainable long term development plan. However, the exclusion of local and national apparatus of the states in the planning and implementing phase, which will result in the beneficiaries being the passive object rather than being active subject of the program. Passive aid recipient will only benefit the beneficiaries for short-term benefit of the program.

LRRD: Rehabilitation, Reconstruction and Developmental phase in Post Tsunami:

The causal relationship between vulnerability and underdevelopment leading to long- term developmental plan is best understood by inclusion of LRRD in RR phase. Only through participation and capacity building will create full ownership and legitimacy of the local communities in the programmes. This is relatable toward achieving LRRD in RR process. However again this depends on the quality and outcome from need assessment in the early phase of emergency relief and humanitarian assistance. The assessment and calculation of effect of disasters by encouraging mass participation from AC equally helps us understand which aspects of capacity building had been affected. Besides helping the donors and state to understand what are the need of the AC and which important aspects of the populations has been mostly affected, it should entail how and who should be responsible in mitigating the effects in aftermath of the disasters. Here coordination between various stakeholder and agencies from government and non-governmental organization is equally responsible in leading an effective post disaster reconstruction. Somehow the best way to measure the outcome of the task of this agencies government or non-government's long term developmental programmes and projects can only be measured by studying the developmental phase after the RR ends.

Link between Relief, Rehabilitation and Development was a concept developed with the effort of international humanitarian agencies especially the multi mandated agencies in overcoming dilemma between short term humanitarian assistance and long term development cooperation in post disaster and post conflict emergencies. It's a unique term coined to analyse how much developmental aspect can be absorb into the humanitarian emergencies even from the first phase that is relief effort [9]. Emphasizing the tangible outcome of development in the developmental phase alone cannot easily materialized and needed to start as early as the relief effort start during the beginning of emergencies. LRRD also accentuate the importance of focusing on the perspectives of receiving end of the aid, which are the beneficiaries of the aid also known as the most affected communities of the emergencies [9].

Given the nature of emergencies fell into both categories which is post disaster and post conflict where both requires the same attention of including development as the final solution by building their capacities as communities and avoiding relying on international assistance alone. As for this paper, only the post disaster aspect will be the major focus, even though the historical part of the case studies heavily inclined toward post conflict and impossible to be separated 
the two but it will be included partly to explain what kind of hurdles faces the international humanitarian agencies in their developmental work in Aceh. The discourse for post disaster takes a different course where the main focus attention was how to reduce disaster risk through development, which enshrined in most aspects of NGOs work in Aceh. The best way to differentiate between the post conflict and post disaster reconstruction is the inclusion of Disaster Risk Reduction (DRR) as another important component to increase development in LRRD based RR [9].

So far almost nothing much has been written on the development phase after this five years' period from the beneficiaries' perspectives. Most past research on RR in Aceh indicates that there is a crucial need to further investigate the development part of the RR phase. Further there is no specific research done from the period of 2009 till recent focusing at how does the RR period has contributed in helping lift the local communities to cope into the transition between the RR and development phases (2009-2013).

However, there are some reports from Tsunami Evaluation Coalition (TEC) that tried to examine the Links between Relief, Rehabilitation and Development (LRRD) effects on RR phase and its impact on the long-term development in reconstructing Aceh. The evaluation took place between mid-2005 to end of 2006 which was too early to extract the outcome of programmes where most INGOs was still underway to implement their developlment plan in Aceh. The evaluation needed a close monitoring process where ample time is to be given to both the INGOs and the beneficiaries to plan and implement to run the program smoothly. Evaluation of LRRD should reflect how has the RR has impact on the development phase. Besides there are lots of rising issues that took place during the implementation of the programmes which has been evaluated within three to six months. This needed to be included in the evaluation process as TEC claims the tsunami LRRD project is considered as learning process for most international agencies involved. However, to drive conclusion out of something that still in progress would be unfair to both the INGOs and the beneficiaries of Tsunami programmes.

As this research focuses on the impact of the development on the capacity building of the beneficiaries in Aceh, the report was useful in examining the pros and contras of the agencies involved in tsunami RR and development process. This research found that focusing on the development phase is crucial because after the RR phase ended in 2009, most international and national agencies left the region had leaving the community behind to function in their own full capacity regardless of their preparedness to govern and rule. The local communities were supposed to be prepared with sufficient skill and knowledge from the knowledge and skill transfer programmes such as 'train the trainer' and to continue to progress toward a sustainable life generated by their capacity as a community. They were also expected to function well as a community without foreign supervision and observation. Here the local government and governing bodies plays an important role in taking over the module and transition planned by INGOs. Sadly, the lacks of institutional building and human capacity are slowing down the transition process.

In order to measure the contribution of RR phase to the community capacity building, their level of participation in the programmes and projects in whole recovery, rehabilitation and reconstruction phase need to be studied because it plays an important role and has a deep impact on their transition to the development phase. Their level, type and involvement in participation in these phases contribute equally to their capacity building of individual and larger scale as community empowerment.

The communities' participations in the programmes and project in post tsunami reconstruction represent the empowerment of the individual as part of community capacity building. The process and level of beneficiaries' participation depend on the INGOs programmes and projects patterns. The participation chart in the theoretical and conceptual part should help explain the link between the type of participation and its impact on empowerment of the beneficiaries by analyzing the level of inclusion of agenda, actor in control, level of consultation with local, planning and targeted recipient in the RR programmes and projects.

Past researches on level of participation in Aceh had indicated participation in every phase of post disaster in Aceh contributed to the community capacity building and empowerment toward self reliance comunity. This can be explained best by looking at the component of participation in capacity building. Obviously some early analysis from data collection indicate the practice in Aceh from the recovery, throughout rehabilitation and reconstruction has fall under this two patterns, which is mainly manipulation and consultation. However past findings also indicate the need for a further research to measure the impact of participation in RR programmes and projects in post tsunami reconstruction among the beneficiaries in the developmental phase.

Capacity Building in Aceh post-tsunami RR: Development in Aceh:

The link between relief, rehabilitation and development (LRRD) in post disaster, RR needed to consider all aspects that affected equally by the disaster [9]. Here there are two different types of reconstruction, first the physical aspects and the human aspects. Both need to be rehabilitated and reconstructed to reach maximum results of successful RR. The rehabilitation process in order to reduce the vulnerability level of affected communities in post disaster environment is very crucial in long-term developmental planning. Here the pre-existing risk, hazard and vulnerability prior to the disaster need to be taken into account for planning of better long-term development plan.

The role of NGOs in assisting the affected communities to reduce their vulnerability level starts as early as post disaster emergency relief and humanitarian phase. The programmes and project designed in the early hours, days and month after disasters are based on general disaster response and mostly focused on relief and alleviating the suffering. It is important to consider a detailed needs assessment to collect useful information and local knowledge which should consider the inclusion of the pre-existing element of the society before getting on with designing, planning and implementing developmental programmes and project in the RR phase. The pre disaster data and ex-post-disaster precise need detailed assessment representing the beneficiary's perspectives [10].

The assessment in the emergency and recovery phase must prioritize the needs of the communities and all considerations must come from both ends of conflict and disaster impact, so that the psychological impact of the conflict not neglected and could equally considered and studied before integrating into different phase of disaster management.

Aceh is one of the good example of tsunami 2004 affected areas of how vulnerabilities have increased the risk when disaster struck on the heavily populated coastal lines. The coastal communities in Banda Aceh the capital and cities of Meulaboh and Callang along the West coast lines of Nanggaroe Aceh Darussalam were among the most affected areas. The absence of early warning system and global tourism based socioeconomic activities has contributed to rapid urbanisation had equally increased the vulnerability level of the coastal communities in Banda Aceh and along West coast of Aceh. Besides being vulnerable due to the socioeconomic reasons at the point of tsunami, the region also politically vulnerable due to the fact that Aceh was a Daerah Operasi Militer (DOM) or Military Operation Region (MOR) for more than three decades prior to Tsunami in December 2004 has its political effect on conflict affected communities.

Aceh is a unique region that has volatile history of political violent since the $17^{\text {th }}$ century. It was a center for trading in South East Asia before the war between English and Dutch dominated the region in the $17^{\text {th }}$ century. Later when Indonesia was in war with the Netherlands, Aceh was invaded and occupied continuously until the Japanese invasion in 1942. Under the United Nations brokered agreement between Dutch and Indonesia, Aceh was transferred to Indonesia, as former colonial territory of Dutch East Indies despite never formally incorporated officially as Dutch colonial possessions. Since 1950, the Javanese from the main Java Island had dominated Aceh's economy with the presence of Indonesian military. This continued with repressive autonomy with limited freedom to practice religious, cultural and educational policy [1].

In 1976, the Gerakan Aceh Merdeka (GAM) or Free Aceh Movement, an armed résistance group that has continued fighting for Acehnese's Independent from the repressive Indonesian government. The declaration of Martial Law in 2003 and in 2004 the situation gone from bad to worst when a state of civil emergency which made it impossible for any local to operate or international agency to enter Aceh let alone to operate in the region. The tsunami that hit Aceh on the eve of Christmas 2004 is the largest humanitarian operation in the world. The large media attention and scale of the disaster in Aceh has forced the Indonesian government to open Aceh to the world and had to lift the state of civil emergency in Aceh on 18 May 2005 [1].

The political conflict between central government and GAM has heavy toll on Aceh socioeconomic development. The protracted conflict had deprived the region with continues violent conflict and oppression. As history tells that Aceh are highly politically violent region due to its natural resources and strategic reasons even prior to tsunami in 2004. So Aceh has experienced both 'manmade' and 'natural disasters' which makes it the best illustrative case study of multiple risk of underdevelopment from both situations.[17] [16] The tsunami did not only multiply the threat but also opened up the opportunity to address threats via humanitarian and developmental program in the post tsunami RR phase.

The combination of factors such as lack of Disaster Risk Reduction (DRR), violence and turmoil, rapid urbanisation and tsunami has affected communities. These factors had kept Aceh being underdeveloped region even prior to tsunami. The prolonged conflict environment meant that existing capacity building was already in jeopardy.

Other socioeconomic aspect that is a part of economic development within participatory development paradigm has gone from bad to worse due to tsunami. 
As a post conflict region, Aceh fell into the categories where reoccurrence of violent conflict had led to underdevelopment. The pre-existing fragility of the affected population has increased due to the high mortality in conflict related crisis than the intensity of the conflict itself. The deep-rooted issues of underdevelopment in Aceh due to pro long conflict have further indirectly inflicted toward high level of risk and vulnerability of the community when the tsunami hit the region. Here underdevelopment is the main point relating towards capacity building.

From a socioeconomic and livelihood sustainability perspective, the inclusion of DRR as main component of long term developmental planning is very crucial to avoid the reoccurring and relapsing back to state of vulnerability. The importance of DRR needed to be emphasized in every RR phase and not only in Disaster Mitigation aspects, which is obvious in the case of Aceh. Here the socioeconomic sustainability was given less priority but somehow disaster mitigation related programmes seems very important from the affected communities' perspectives. Emerging issues within socioeconomic and livelihood sustainability should be prioritizing in reducing the vulnerabilities among conflict and post tsunami affected communities separately. Beside reducing the chance of relapsing back to underdevelopment state, inclusion of DRR in each phase of RR is best the long term development plan needed for post tsunami recovery and continued all the way to post tsunami reconstruction phases.

As post tsunami reconstruction in Aceh requires more than just physical reconstruction and developmental phase would make it a complex process. Aceh is a very unique in the sense that the region suffered both manmade and natural disaster. It requires a combination of political and development framework analysis to tackle the deep-rooted problem in Aceh a post conflict and post tsunami region. NGOs work here involves more than just delivering humanitarian assistance and socioeconomic programmes.

In Aceh, the issue of integrating DRR in its RR phase was rather a problematic one. Basically there are two mainstreams related to DRR known as 'building back better' (BBB) and 'building back safely' (BBS). Both have its logic, benefit and flaws that had been advantage or disadvantages to the communities especially during the RR. In some way both mainstreams have helped to integrate the DRR aspects in BBS or the LRRD aspects in BBB within the affected communities in the RR. Most INGOs in the findings of this research found themselves juggling between the two either to reach their target which is their upward accountability toward the donors or fulfilling downward accountability by providing and assisting in meeting the need and satisfaction of their beneficiaries.

The main issue being contested here is rather considering which one need to be prioritize in optimizing the best strategies to achieve long-term development plan. The task of interpreting the two mainstreams from the beneficiaries' perspective can be termed as "community based reconstruction" interpreted as BBB and "contractor based reconstruction" interpreted as BBS. Both mainstreams have its own individual interpretations, issues and challenges for both the NGOs and the $\mathrm{AF}$ to overcome.

However what matters here is to justify how does via these two main streams within DRR and LRRD framework in targeting to reduce the level of vulnerability from the beneficiaries' perspective. Findings from the past literatures based on NGOs and donors' perspectives. In relation to this research, most findings from past literature that inclined focusing on what and how DRR and LRRD [15] aspect from the INGOs perspectives which lead toward biasness on measuring development on the affected communities side. The research also found that its best to look from both sides; the INGOs and their beneficiaries in analyzing how far the long term development plan has been materialized in helping the capacity building and help sustaining development at the local level within the affected communities.

Conclusion:

This paper tries to explore the roles of NGOs in RR phase in post tsunami reconstruction Aceh, Indonesia. Finding from primary empirical and secondary data both inclined toward the importance of inclusion of LRRD in planning, designing and implementation of programmes and projects in PTR. The role of NGOs in this process deemed crucial in encouraging local participation (partnership and ownership), which are critical in achieving local ownership and legitimacy of the programmes. It is a two-way process between NGOs' role as developmental agencies and beneficiaries' active participatory to enhance local capacity building. The PTR programmes and projects need to emphasize the importance of community-based development to encourage active and full participation. Then the personal and economic security is attainable thru participation in the programmes and projects. However, the capacity building process is within reach when the programmes were design to include the existing local assets and human capacities thru local participation, which promises better outcome of the PTR for the beneficiaries.

\section{REFERENCES}

[1] Kenny, S., 2005. Reconstruction in Aceh: Building whose capacity? Community Development Journal, 42(2): 206-221. doi: 10.1093/cdj/bsi098

[2] Murray, M.C.a.S., 2010. The Voices of International NGO staff. Post-Disaster Reconstruction: Lessons from Aceh. M. F. Clarke, Ismet; Kenny, Sue. Hoboken, Earthscan, pp: 155-184.

[3] Hillhorst, D., 2003. The Real World of NGOs: Discourses, Diversity and Development. London \& New York, Zed Books Ltd.

[4] Kenny, S., 2005. "Reconstruction in Aceh: Building whose capacity?" Community Development Journal, 42(2): 206-221.

[5] Zeccola, P., 2014. Linking disasters in Aceh: human security, conflict and the 2004 Indian Ocean tsunami. Human Security and Natural Disasters. C. B. Hobson, Paul; Cameron, Robin London and New York, Routledge, pp: 127-139.

[6] Kenny, S., 2010. Capacity Building in Indonesia: Building What capacity? In Challenging Capacity Building: Comparative Perspectives. New York: Palgrave Macmillan., pp: 156-184.

[7] Murray, M.C.a S., 2010. The Voices of International NGO staff. Post-Disaster Reconstruction: Lessons from Aceh. M. F. Clarke, Ismet; Kenny, Sue. Hoboken, Earthscan, pp: 155-184.

[8] Kenny, S., 2010. Capacity Building in Indonesia: Building What capacity? In Challenging Capacity Building: Comparative Perspectives. New York: Palgrave Macmillan., pp: 156-184

[9] Fabbri, M.B.-S.a.P., 2005. Links between relief, rehabilitation and development in the tsunami response: A Review of the debate. LRRD. London ALNAP Oversea Development Institutions, pp: 1-49.

[10] Wapner, P., 2008. Civil Society. The Oxford Handbook on the United Nations. S. Thomas G. Weiss and Daw. Oxford, Oxford Handbooks Online, pp: 254262.

[11] Christoplos, I., 2006. Links between relief, rehabilitation and development in the tsunami response. Tsunami Evaluation Coalition, pp: 1-100.

[12] Kenny, S., 2010. Capacity Building in Indonesia: Building What capacity? In Challenging Capacity Building: Comparative Perspectives. New York: Palgrave Macmillan., pp: 156-184.

[13] Mardhatillah, F., 2010. The Role and Experiences of Badan Rehabilitasi and Rekonstruksi (BRR). Post-Disaster Reconstruction: Lessons from Aceh. M. F. Clarke, Ismet Kenny, Sue. Hoboken, Earthscan, pp: 186-209.

[14] Clarke, M.F., Ismet Kenny, Sue, 2010. Reconstruction through Participatory Practice. Post Disaster Reconstruction: Lesson from Aceh. London, Earth scan., pp: 79-104.

[15] Christoplos, I., 2006. Links between relief, rehabilitation and development in the tsunami response. Tsunami Evaluation Coalition, pp: 1-100.

[16] Zeccola, P., 2011. "Dividing Disasters in Aceh, Indonesia: Separatist Conflict and Tsunami, Human Rights and Humanitarianism " Disasters, 35(2): 308328.

[17] Zeccola, P., 2014. Linking disasters in Aceh: human security, conflict and the 2004 Indian Ocean tsunami. Human Security and Natural Disasters. C. B. Hobson, Paul; Cameron, Robin London and New York, Routledge, pp: 127-139. 